\title{
Comparison of three statistical methods for earthquake-induced landslides susceptibility in Lushan region China
}

\author{
Rui Liu ${ }^{1,3}$, Luyao Li $^{*}{ }^{1}$, Zili Lai ${ }^{3}$, Xin Yang ${ }^{1}$ \\ ${ }^{1}$ College of Geophysics, Chengdu University of Technology, Sichuan 610059, China \\ ${ }^{2}$ Key Lab of Earth Exploration and Information Techniques of Ministry Education, Chengdu University of Technology, Sichuan \\ 610059, China \\ ${ }^{3}$ Dongpo district, Meishan, Sichuan province, Meishan Housing and Urban-Rural Construction Bureau, Sichuan 620000, China
}

\begin{abstract}
This paper adopts three models including the logistic regression (LR), support vector machine (SVM), and random forest (RF) to study the susceptibility distribution rule of susceptibility distribution of earthquakes induced landslides. The Area Under the Receiver Operating Characteristic (ROC) curve (AUC) and Ratio were used for evaluating the model's accuracy and mapping availability susceptibility assessment. The result shows that RF has the best performance in the susceptibility assessment of earthquake-induced landslides in the Lushan region of China.
\end{abstract}

\section{Introduction}

The LR and RF models were the two most commonly used models in studies for that they were effective in mapping landslide susceptibility, and currently, the SVM are relatively mature in landslides susceptibility assessment. For this reason, the RF, LR and SVM models were selected in this study to develop earthquake-triggered landslides susceptibility models in Lushan[1].

\subsection{Study area}

The study area locates in the west of the Sichuan Basin in China and the southern section of the Longmenshan seismic fault zone. The elevation of the study area ranges from $541 \mathrm{~m}$ to $2929 \mathrm{~m}$ and presenting the lower from north to south. In recent years, there were repeatedly found Wild giant panda in Lushan area according to official news reports in China.Unfortunately, at 08:02 am on April 20, 2013, a strong earthquake (MS7.0) struck the Lushan Town.

\section{Materials and methods}

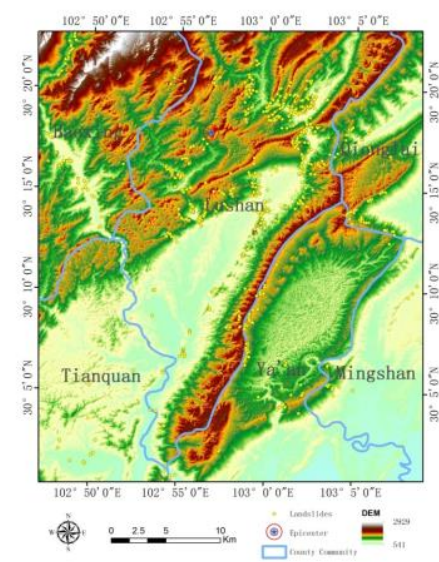

Figure 1. The study area and its geographic setting with the location of the epicenter of the Lushan earthquake, West of Sichuan Basin. 


\subsection{Data sources}

Remote sensing data include the unmanned aerial vehicle (UAV) data $(0.5 \mathrm{~m})$, Ziyuan-3 surveying satellite image (ZY-3, 2.1m) and Landsat-5 satellite image (30m). The terrain data is ASTER GDEM (V2.0, $30 \mathrm{~m}$, UTM/WGS84), derived from NASA (http://www.nasa.gov/). The seismic data is the Peak ground acceleration (PGA), derived from the USGS (http://glovis.usgs.gov/). This paper identified 944 landslides that are triggered by the quake.

\subsection{Landslide predisposing factors}

By summarized the data and similar researches[2-9], this paper has selected the following static predisposing factors and shown :

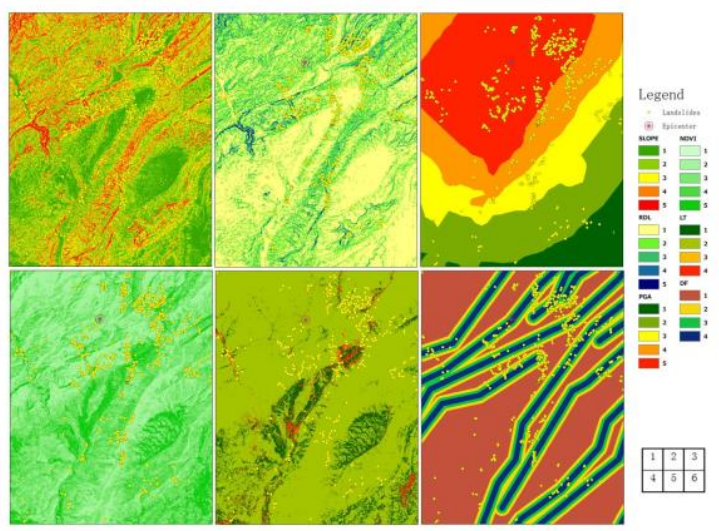

Figure 2. The landslide predisposing factors. 1) Slope degree (Slop), 2) Relief degree of the land surface (RDL), 3) Peak ground acceleration (PGA), 4) Normalized difference vegetation index (NDVI), 5) Land use types (LT), 6) The distance from the seismic faults (DF).

\section{Methods}

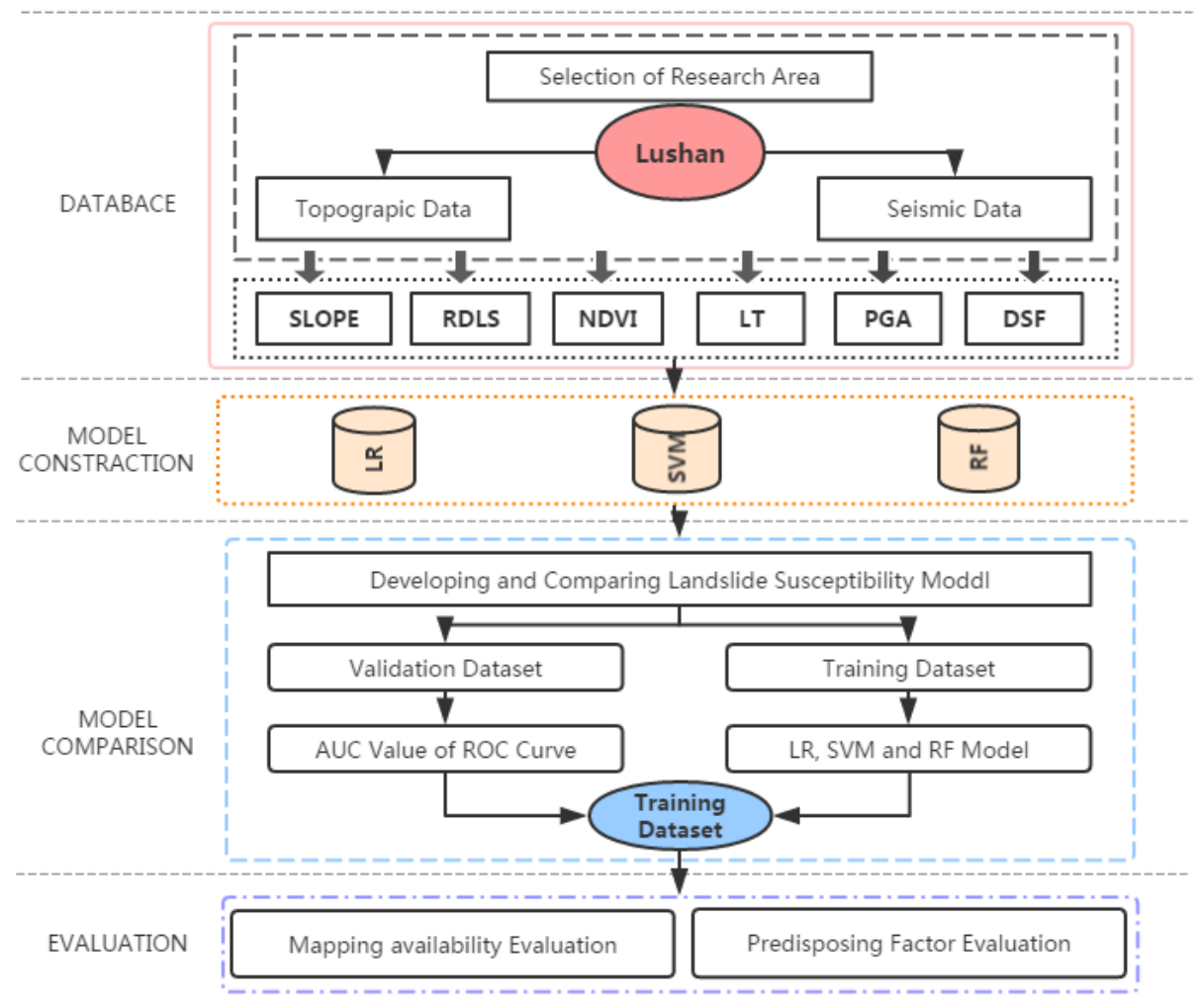

Figure 3. Flowchart of methodology 


\section{$4 \quad$ Results and discussion}

The application of these three models to the whole study area has delivered three landslide susceptibility maps. Figure 4 depicts the result of those models.

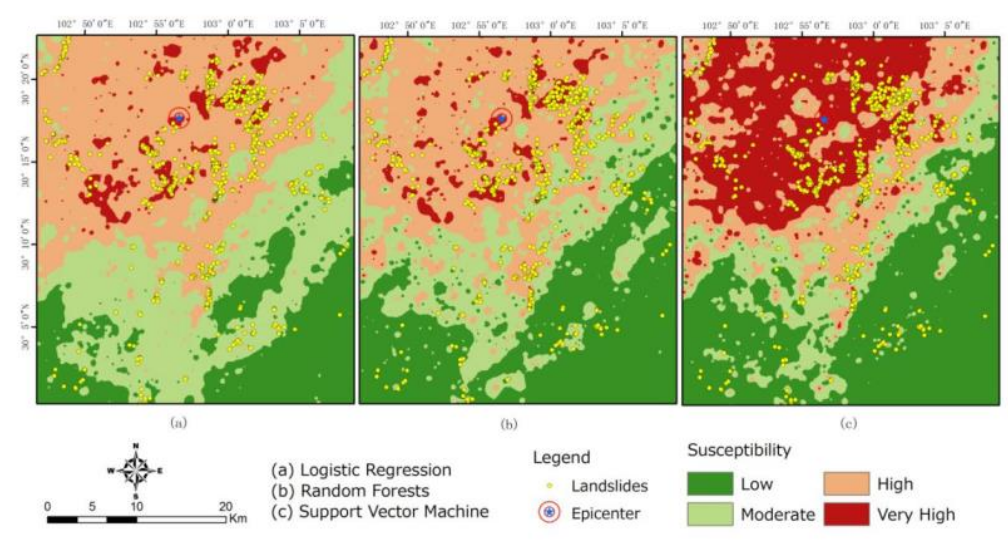

Figure 4. Landslides susceptibility maps produced by three methods.

The areal proportion of the high and very high susceptibility classes is $48.8 \%$ for the LR, $38.4 \%$ for the RF, and $43.9 \%$ for SVM.

\section{Conclusions}

The result reveals that RF has the best prediction performance. Many impact factors influence the occurrence of landslides, and each impact factors has a different influence. This study does not consider the lithologic factor, it needs further studies to prove that the statistical method could get a great result under the condition of the lack of landslide impact factors[10]. Frankly speaking, it $s$ far from adequate in aid of preservation efforts for the giant panda habitat, there is much more to do. So we will take more areas like Lushan where are both landslide prone areas and wild giant panda habitats in flow-up research with higher precision models which we are trying to further improve.

\section{Acknowledgments}

Foundation of SiChuan Educational Committee (No.14ZB0071), Science \& Technology Department of SiChuan Province Technology Support Program (No.2012FZ0018) and Research Center for Petroleum Development of Sichuan Province (No.SKB10-11) has supported the research work. The authors would like to express appreciations to the stuffs in their lab for their valuable comments and contributions.

\section{References}

1. Naghibi S A, Pourghasemi H R, Dixon B, 2016. GIS-based groundwater potential mapping using boosted regression tree, classification and regression tree, and random forest machine learning models in Iran. Environmental Monitoring \& Assessment. 188(1):1-27.

2. Bourenane H, Bouhadad Y, Guettouche M S, 2014. GIS-based landslide susceptibility zonation using bivariate statistical and expert approaches in the city of Constantine (Northeast Algeria). Bulletin of Engineering Geology \& the Environment. 74(2):337-355.

3. Wan S, 2009. A spatial decision support system for extracting the core factors and thresholds for landslide susceptibility map. Engineering Geology. 108(3-4):237-251.

4. Carrara A, 1983. Multivariate models for landslide hazard evaluation. Journal of the International Association for Mathematical Geology. 15(15):403-426.

5. Elayaraja S, Ganapathy G P, 2015. Evaluation of seismic hazard and potential of earthquake-induced landslides of the Nilgiris, India. Natural Hazards. on line first (3):1-19.

6. Myronidis D, Papageorgiou C, Theophanous S, 2015. Landslide susceptibility mapping based on landslide history and analytic hierarchy process (AHP). Natural Hazards. 1-19.

7. Feng Z, Tang Y, Yang Y, et al., 2008. Relief degree of land surface and its influence on population distribution in China. Journal of Geographical Sciences. 18(2):237-246.

8. Zhou Hongjian, 2015. Risk Assessment of Disaster Chain: Experience from Wenchuan Earthquake-induced Landslides in China. Journal of Mountain Science. 12(5):1169-1180.

9. Lee C T, Huang C C, Lee J F, 2008. Statistical approach to earthquake-induced landslide susceptibility. Engineering Geology. 100(12):43-58.

10. Lee S, Talib J A, 2005. Probabilistic landslide susceptibility and factor effect analysis. Environmental Geology. 47(7):982-990. 